\title{
Differential effects of garcinol and curcumin on histone and p53 modifications in tumour cells
}

Hilary M Collins ${ }^{1}$, Magdy K Abdelghany ${ }^{1,3}$, Marie Messmer ${ }^{1}$, Baigong Yue ${ }^{1}$, Sian E Deeves ${ }^{1}$, Karin B Kindle ${ }^{1}$, Kempegowda Mantelingu², Akhmed Aslam, G Sebastiaan Winkler', Tapas K Kundu ${ }^{2}$ and David M Heery ${ }^{1 *}$

\begin{abstract}
Background: Post-translational modifications (PTMs) of histones and other proteins are perturbed in tumours. For example, reduced levels of acetylated H4K16 and trimethylated H4K20 are associated with high tumour grade and poor survival in breast cancer. Drug-like molecules that can reprogram selected histone PTMs in tumour cells are therefore of interest as potential cancer chemopreventive agents. In this study we assessed the effects of the phytocompounds garcinol and curcumin on histone and p53 modification in cancer cells, focussing on the breast tumour cell line MCF7.
\end{abstract}

Methods: Cell viability/proliferation assays, cell cycle analysis by flow cytometry, immunodetection of specific histone and p53 acetylation marks, western blotting, siRNA and RT-qPCR.

Results: Although treatment with curcumin, garcinol or the garcinol derivative LTK-14 hampered MCF7 cell proliferation, differential effects of these compounds on histone modifications were observed. Garcinol treatment resulted in a strong reduction in $\mathrm{H} 3 \mathrm{~K} 18$ acetylation, which is required for $\mathrm{S}$ phase progression. Similar effects of garcinol on H3K18 acetylation were observed in the osteosarcoma cells lines U2OS and SaOS2. In contrast, global levels of acetylated H4K16 and trimethylated H4K20 in MCF7 cells were elevated after garcinol treatment. This was accompanied by upregulation of DNA damage signalling markers such as YH2A.X, H3K56Ac, p53 and TIP60. In contrast, exposure of MCF7 cells to curcumin resulted in increased global levels of acetylated H3K18 and H4K16, and was less effective in inducing DNA damage markers. In addition to its effects on histone modifications, garcinol was found to block CBP/p300-mediated acetylation of the C-terminal activation domain of p53, but resulted in enhanced acetylation of p53K120, and accumulation of p53 in the cytoplasmic compartment. Finally, we show that the elevation of H4K2OMe3 levels by garcinol correlated with increased expression of SUV42OH2, and was prevented by siRNA targeting of SUV42OH2.

Conclusion: In summary, although garcinol and curcumin can both inhibit histone acetyltransferase activities, our results show that these compounds have differential effects on cancer cells in culture. Garcinol treatment alters expression of chromatin modifying enzymes in MCF7 cells, resulting in reprogramming of key histone and p53 PTMs and growth arrest, underscoring its potential as a cancer chemopreventive agent.

Keywords: Garcinol, Curcumin, Acetyltransferase, HAT inhibitor, Histones, p53, Post-translational modifications, H4K20Me3, SUV420H2, TIP60

\footnotetext{
* Correspondence: david.heery@nottingham.ac.uk

${ }^{1}$ Gene Regulation Group, Centre for Biomolecular Sciences, School of

Pharmacy, University of Nottingham, University Park, Nottingham NG7 2RD,

United Kingdom

Full list of author information is available at the end of the article
}

\section{Biomed Central}

(c) 2013 Collins et al.; licensee BioMed Central Ltd. This is an Open Access article distributed under the terms of the Creative Commons Attribution License (http://creativecommons.org/licenses/by/2.0), which permits unrestricted use, distribution, and reproduction in any medium, provided the original work is properly cited. 


\section{Background}

Enzymes that modify chromatin and associated proteins by the addition or removal of acetyl or methyl groups play a key role in genome regulation [1]. These and other PTMs generate a combinatorial histone code that demarcates chromatin regions for transcription activation or repression [2]. Histone PTMs are also critical for other genomic functions, such as DNA replication and induction of repair mechanisms at sites of DNA damage [3]. Histone modifications act as signals that are 'read' by sensory proteins containing bromodomains, PHD fingers and other domains, many of which function as coregulators of DNA-binding transcription factors [4]. While some core histone PTMs (H3K9Ac, H3K18Ac, H3K27Ac, H3K4Me3) are commonly associated with active genes, others (H3K9Me2/3 and H4K20Me3) are more usually indicators of repressed genes and heterochromatin $[1,2]$. Specific histone PTMs such as phosphoS139H2AX (known as $\gamma \mathrm{H} 2 \mathrm{~A} . \mathrm{X}$ ) are upregulated by DNA damage signalling, and are necessary for DNA repair $[3,5]$. Not surprisingly, dramatic changes in global histone PTMs are observed in cancer, such as the observed reduction of H4K16Ac and H4K20Me3 levels in cancer cell lines, described as hallmarks of cancer [6]. This was recently confirmed in tissue microarray studies using large numbers of breast and prostate tumours [7-10]. Interestingly, H4K16Ac and H4K20Me3 are also implicated in DNA damage checkpoints $[11,12]$ which are disrupted in cancer cells. Thus, drug-like molecules that target chromatin modifying enzymes to reprogram selected histone PTMs in tumour cells may have potential as cancer chemopreventive agents.

A number of natural and synthetic molecules that inhibit histone acetyltransferase (HAT) or histone deacetylase (HDAC) activities have been described. HDAC inhibitors have shown promise in clinical trials as anticancer therapies, especially when used in combination with other chemotherapies. Less is known regarding the in vivo effects of molecules that can inhibit lysine acetyltransferase activity in vitro. Natural products that can block the activity of histone acetyltransferases in vitro have been isolated from plants [13-15]. Curcumin (diferuloylmethane) is derived from the turmeric plant Curcuma longa and inhibits CBP/p300 acetyltransferase activity in vitro, whereas PCAF appears insensitive to this compound at concentrations that inhibit p300 [16]. Garcinol is a polyisoprenylated benzophenone present in Garcinia indica fruit rind that also inhibits both $\mathrm{CBP} / \mathrm{p} 300$ and PCAF HAT activities [17]. In this study we report that garcinol treatment blocks MCF7 cell proliferation, which is accompanied by induction of DNA damage repair markers and altered expression of selected histone/p53 modifying enzymes. This results in reprogramming of selected histone and p53 PTMs, and in particular can reverse the loss of H4K20Me3 in tumour cell lines. Our results provide insight into the biological effects of garcinol in altering histones and p53 PTMs in cancer cells, thus underscoring its potential as a lead for the development of new anticancer agents.

\section{Methods \\ Acetyltransferase inhibitors}

Curcumin was purchased from Sigma (C-1386). Garcinol was extracted as described previously [17], and LTK14 was synthesised from garcinol as previously described [18]. Inhibitor compounds were dissolved in DMSO (garcinol compounds) or ethanol (curcumin).

\section{Cell culture}

The breast cancer cell line MCF7, and the osteosarcoma cell lines U2OS and SaOS2 were maintained in Dulbecco's Modified Eagle Medium (DMEM) supplemented with $10 \%$ foetal calf serum (FCS) and $2 \mathrm{mM}$ glutamine at $37^{\circ} \mathrm{C}$ in $5 \% \mathrm{CO}_{2}$.

\section{Cell viability/proliferation assays}

Viable cells were quantified by a standard MTT (3-(4,5dimethylthiazol-2-yl)-2,5-di phenyltetrazolium bromide) reduction assay. Cell-mediated reduction of MTT was determined by reading absorbance at $550 \mathrm{~nm}$. To measure the effects of curcumin, garcinol and LTK14 on cell viability and proliferation, MCF7 cells were seeded into 96-well microtitre plates at a density of $5 \times 10^{3}$ cells/per well and allowed to adhere overnight. The initial density of viable cells prior to addition of inhibitors (denoted as time $\mathrm{t}=0$ ) was determined in a control plate. Inhibitors were prepared immediately before use and added to test wells at the following concentrations $(0,2,8,15,20 \mu \mathrm{M})$ at time zero. After addition of inhibitors or vehicle, cells were cultured for a further $24 \mathrm{hrs}$ before measurement of MTT activities. Data were presented as the average of 5 replicates per condition.

\section{Western blots and immunocytochemistry}

For western blotting and immuno-cytochemistry cells were cultured in DMEM supplemented with 10\% FCS and $2 \mathrm{mM}$ glutamine at $37^{\circ} \mathrm{C}$ in $5 \% \mathrm{CO}_{2}$, in the presence or absence of HAT inhibitors for 24 hours. Histones were acid extracted as described [19] for use in western blotting. For immunocytochemical detection of specific proteins or PTMs, cells were plated onto coverslips in 24 well plates for 24 hours. Following incubation with the inhibitors or vehicle, the cells were fixed in $4 \%$ paraformaldehyde and permeabilised using $0.2 \%$ Triton X-100 followed by a PBS wash, blocking in 3\% BSA, and addition of primary antibodies as follows: pan acetyl H3 1:100, pan acetyl H4 1:100, Phospho-Ser139 H2A.X 1:75 (Upstate); H4K16Ac 1:200 (Chemicon); H3K9Ac 
1:1000, Н3К18Ac 1:200, H4K20Me3 1:200, TIP60 1:1000, p53K120Ac 1:100, p53K386Ac 1:200, p53K373/382Ac 1:100 (Abcam); p53(D01) 1:100 (Santa Cruz). After 1 hour incubation, the cells were washed in PBS and incubated with an appropriate secondary antibody (1:500 dilution). Images were captured on a Zeiss LSM510 Meta confocal microscope.

For western blotting, the above antibodies were used at a dilution of 1:500. In addition, other primary antibodies were H3 1:2000 (Santa Cruz); hMOF 1:200, TIP60 1:500 (Genetex); SIRT1 1:100, SUV420H1/H2 1:100, H3K9Me3 1:500 (Abcam) and H3K56Ac 1:500 (Epitomics). Appropriate HRP-conjugated secondary antibodies were used at a dilution of 1:5000 (Santa Cruz).

\section{Flow cytometry}

To assess the effects of HAT inhibitors on the cell cycle, cells were treated with inhibitors or vehicle for 24 hours as described for growth assays, followed by addition of $1 \mu \mathrm{M}$ Bromodeoxyuridine (BrdU) for 2 hours prior to harvesting. Cells were fixed, incubated with propidium iodide to stain DNA and FITC-conjugated anti-BrdU antibody 3D4 (BD Pharmingen), and subjected to bivariate flow cytometry as described previously [20]. To quantify the numbers of cells scoring positive for immunodetection of histone PTMs or SUV420H2 following exposure to HAT inhibitors, treated cells and controls were treated with trypsin, washed three times in PBS and fixed in ice-cold 70\% ethanol. The permeabilised cells were incubated with primary antibodies (H4K20Me3 1:100 and SUV420H1/H2 1:100) and appropriate Alexa Fluor-conjugated secondary antibodies, and DNA labelled using propidium iodide. Cells were washed and resuspended in PBS for flow cytometric analysis using a FacsAria (BD Biosciences). The total number of cell scanning events was limited to 4000 . Appropriate negative controls included unstained cells, PI only, secondary antibody only.

\section{RNA interference}

The following siRNA duplexes were used (Dharmacon Research); SUV420H2 (on-targetplus SMARTpool L018622-02), and nontargeting control siRNA (SMARTpool D-001810-10). MCF7 cells were transfected with siRNA (5 nM) using INTERFERin (Polyplus) following the manufacturer's instructions. At 24 hours post transfection cells were treated with $20 \mu \mathrm{M}$ garcinol and western blotting carried out as above for the PTM H4K20Me3. SUV420H2 transcripts in the siRNA treated cells were measured by RT-qPCR, which was carried out as described previously [20] using the following primers; Fwd 5'cgtgtccactcgtgcttg-3'; Rev 5'ctcagcagcccet catct-3. GAPDH transcript levels were used as the reference gene.

\section{Results}

Acetyltransferase inhibitors arrest MCF7 cell proliferation

We assessed the effects of the acetyltransferase inhibitors curcumin and garcinol on proliferation of MCF7 cells in culture. Range finding experiments showed that concentrations above $20 \mu \mathrm{M}$ of either compound were cytotoxic to MCF7 cells, inducing loss of adherence and cell lysis after $24 \mathrm{~h}$ exposure (data not shown). Thus, to facilitate the correlation of any antiproliferative effects with changes in histone modifications, cell proliferation/viability assays were performed using subcytotoxic concentrations of the HAT inhibitors. MCF7 cells were seeded at a density of $5 \times 10^{3}$ cells/per well and allowed to adhere to plates overnight. MTT assays were performed to measure initial density of viable cells, and the change in cell viability/proliferation after culture for $24 \mathrm{~h}$ in the presence of a dose range $(2-20 \mu \mathrm{M})$ of inhibitors or controls. The initial O.D. $550 \mathrm{~nm}$ readings $(\mathrm{t}=0)$ was 1.07 (shown as 'initial density' in Figure 1A) and after $24 \mathrm{hrs}$ the control (vehicle-treated) cells showed an increase to an average reading of 1.67 O.D. units, indicative of an increase in viable cells due to proliferation. As shown in Figure 1A, in comparison to vehicle, curcumin had a stimulatory effect on the growth of MCF7 cells at the lowest dose $(2 \mu \mathrm{M})$, but hampered cell proliferation at $20 \mu \mathrm{M}$. Inhibition of MCF7 cell growth by garcinol and LTK-14 was observed to be more potent, with a complete block of growth observed at $20 \mu \mathrm{M}$ (Figure 1A). Similar results were obtained using U2OS cells (data not shown).

To confirm the observed effect of HAT inhibitor compounds on MCF7 cell growth, cell cycle analyses were performed using bivariate flow cytometry. As shown in Figure 1B, MCF7 cells exposed to garcinol $(10 \mu \mathrm{M})$ for 24 hours showed a dramatic reduction in the numbers of actively replicating cells (S phase) compared to controls. This was accompanied by a concomitant increase in the G1 population, consistent with reduced proliferation and G1 arrest. Similar results were obtained using the recently described garcinol derivative 14-methoxy-isogarcinol (LTK-14) (Figure 1B) [18]. Thus, at subcytotoxic concentrations, garcinol compounds block the ability of MCF7 cells to successfully replicate their DNA.

Exposure of MCF7 cells to curcumin for 24 hours also resulted in a dose-dependent reduction in the proportion of cells entering $\mathrm{S}$ phase, as indicated in Figure $1 \mathrm{C}$. In contrast to garcinol compounds, curcumin-treated MCF7 cells showed an increase of cells arrested in G2/M (a 4-fold increase over control after $24 \mathrm{hrs}$ ), (Figure 1C). Neither inhibitor induced a substantial increase in the sub-G1 population at the concentrations used, indicating that cells did not undergo apoptosis or cell death during the course of the experiment. 

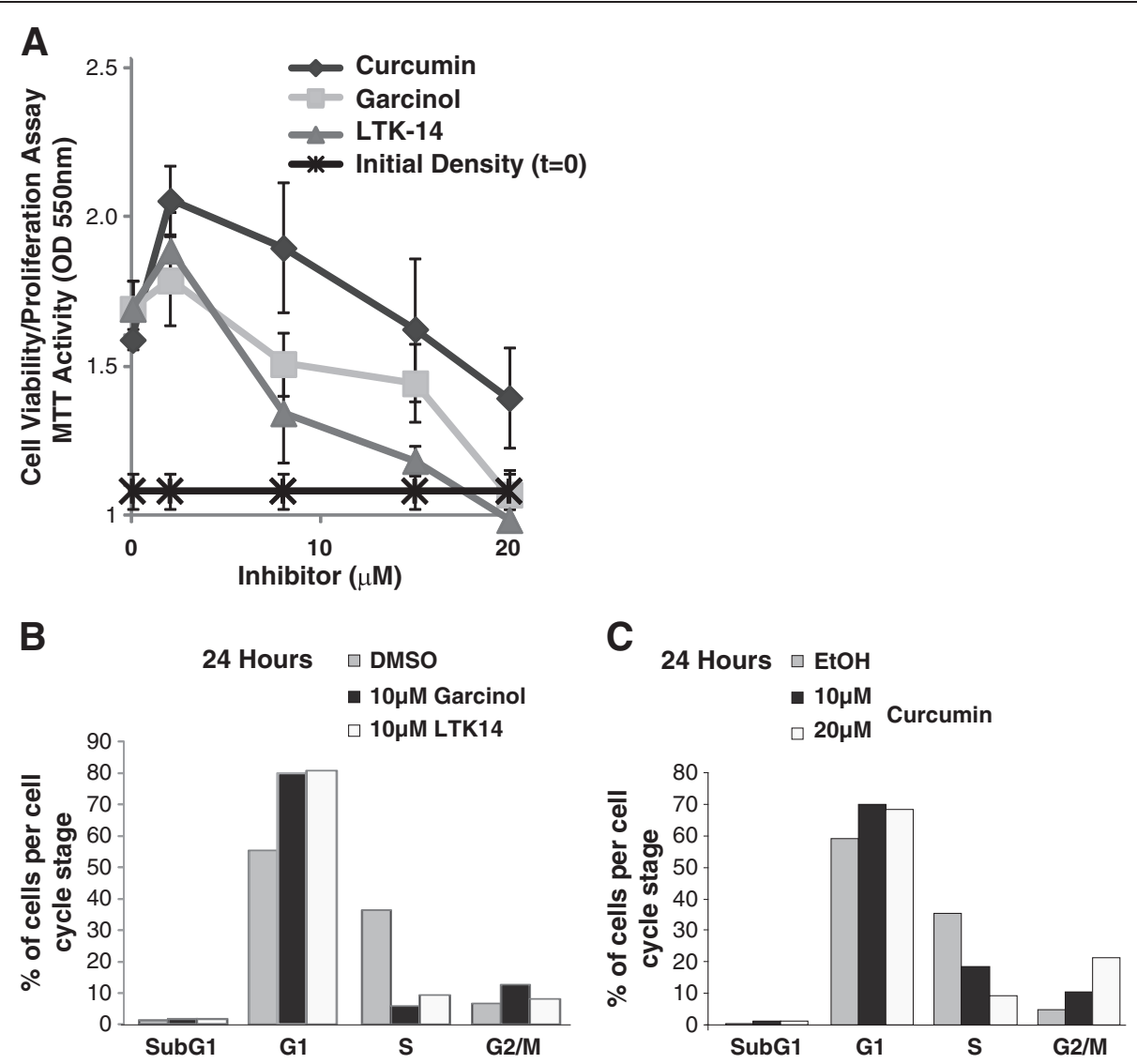

Figure 1 Curcumin, garcinol and LTK-14 impede MCF7 cell proliferation. (A) MCF7 cells were seeded at a density of approximately $5 \times 10^{3}$ cells per well in microtitre plates and allowed to adhere overnight. The initial cell density was determined in a control plate prior to addition of curcumin, garcinol or LTK-14 at the indicated concentrations, or vehicle. After 24 hours, the change in the number of viable cells was estimated using MTT assays (see Methods). The data shown are the means of 5 replicates \pm standard deviations. (B) Cell cycle analyses of MCF7 cells after 24 hours in culture in the presence of garcinol or LTK14 $(10 \mu \mathrm{M})$ or vehicle control. The bar charts show a representative experiment indicating the percentage of cells in G1, S or G2/M phases, and the subG1 population as determined by BrdU incorporation and propidium iodide staining. (C) Cell cycle analyses of MCF7 cells after 24 hours culture in the presence of curcumin (10 $\mu \mathrm{M}$ or $20 \mu \mathrm{M})$ or vehicle control, as described in (B).

\section{Differential effects of curcumin and garcinol on histone PTMs}

We next compared the effects of curcumin and garcinol on bulk histone acetylation levels in proliferating MCF7 cells. Cells were treated with curcumin or garcinol at two sublethal doses $(10 \mu \mathrm{M}$ and $20 \mu \mathrm{M})$ for 24 hours, fixed and subjected to immunocytochemical staining with antibodies to detect pan-acetylated histones $\mathrm{H} 3$ or H4. As shown in Figure 2A, acetylated H3 was readily detected in the nuclei of controls, but stain intensity was reduced after exposure to curcumin, garcinol or LTK14, indicating $\mathrm{H} 3$ hypoacetylation, consistent with previous reports [18]. Similarly, acetyl-H4 staining appeared to decrease after exposure to $10 \mu \mathrm{M}$ of the HAT inhibitors, but surprisingly was detected at similar intensity as control at the higher doses $(20 \mu \mathrm{M})$ of curcumin or garcinol (Figure 2A). This unexpected effect appears to indicate differential and dose-dependent effects of these compounds on histone modifications in MCF7 cells.
To explore this further we next investigated how the acetylation status of specific histone $\mathrm{N}$-terminal lysines is affected by HAT inhibitor treatments. Proliferating MCF7 cells were treated with inhibitor compounds as before, and assessed by immunocytochemistry and western blotting. Acetylation of H3K18, which is a substrate of $\mathrm{CBP} / \mathrm{p} 300$ [22] was not inhibited by treatment with curcumin (up to a concentration of $20 \mu \mathrm{M}$ ) (Figure 2B\&D). In contrast, garcinol treatment of MCF7 cells resulted in reduced staining with the H3K18Ac antibody (Figure 2B) and decreased detection of H3K18Ac by western blotting as confirmed by densitometry analysis (Figure 2D). In contrast, bulk levels of H3K9Ac in MCF7 cells were not altered following exposure to curcumin or garcinol (Figure 2B\&D). Garcinol also reduced H3K18 acetylation in the osteosarcoma cell lines, U2OS and $\mathrm{SaOS} 2$, whereas curcumin treatment resulted in increased detection of H3K18Ac (Figure 2E). Thus, inhibition of $\mathrm{CBP} / \mathrm{p} 300$, or other HATs required for progression 
A
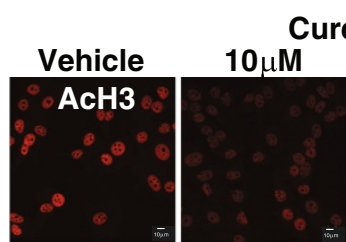

Curcumin
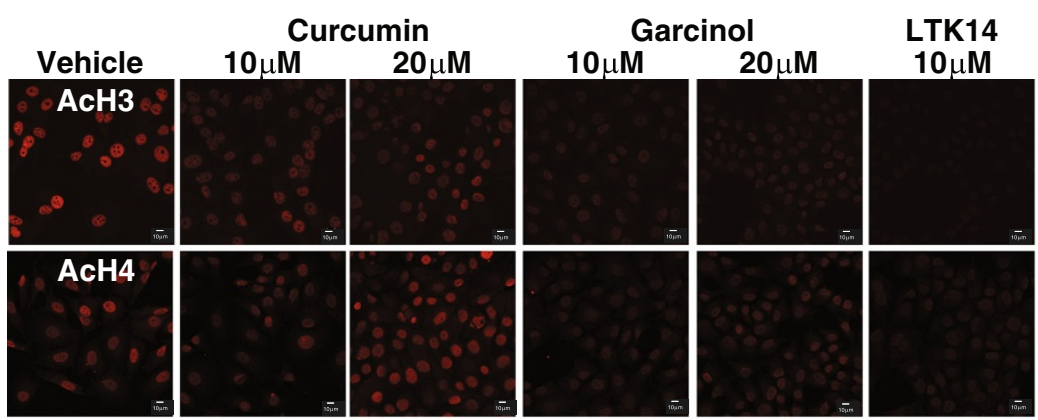

B

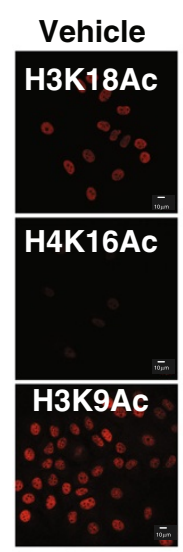

Curcumin

Garcinol
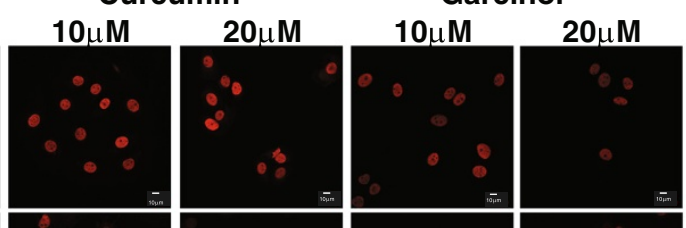

C
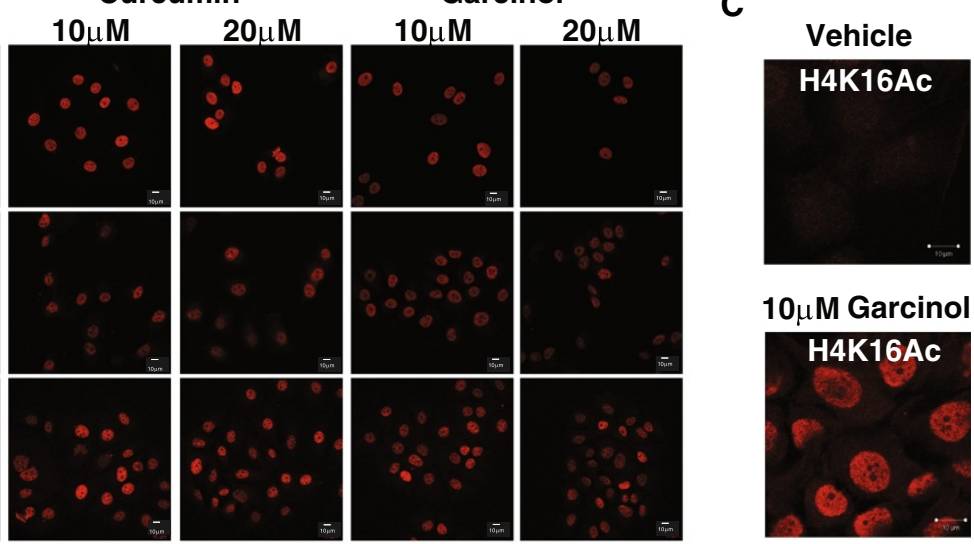

D
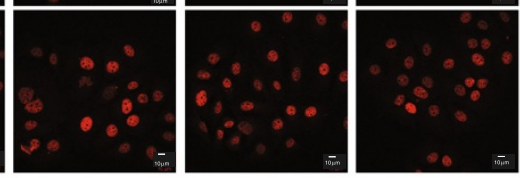

MCF7

Curcumin Garcinol
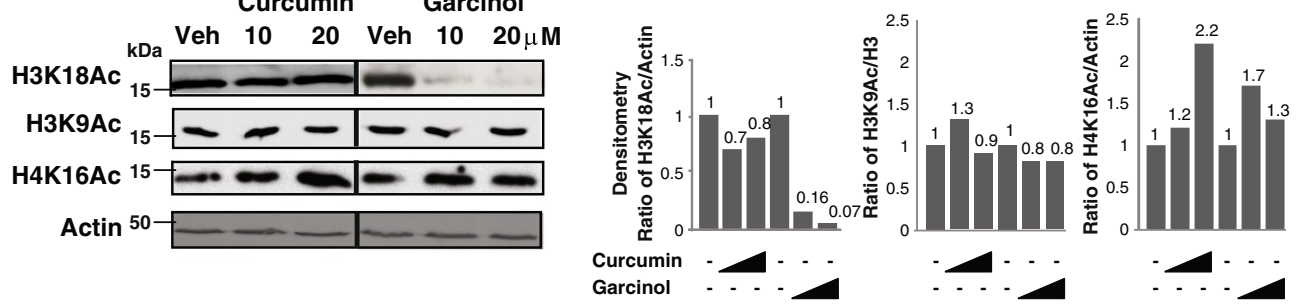

E
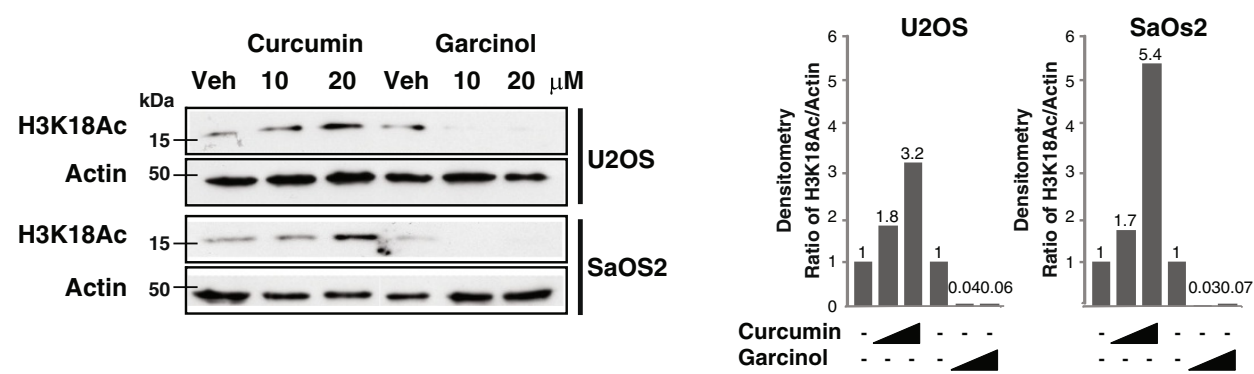

Figure 2 Reprogramming of global histone modifications by garcinol and curcumin. (A) Nuclear staining of MCF7 breast cancer cells with antibodies detecting pan acetyl H3 (top panels) or pan acetyl H4 (bottom panels). Control shows typical staining in the absence of inhibitors (vehicle only), and the effect of treatment with HAT inhibitors at the indicated concentrations are also shown. Scalebar: $10 \mu \mathrm{m}$. (B\&C)

Immunostaining of MCF7 cells following treatment with the indicated concentrations of curcumin or garcinol for 24 hours. Vehicle control is also shown. Histone PTM-specific antibodies were used to reveal H3K18Ac, H4K16Ac and H3K9Ac levels in response to treatment. Scalebar: 10 $\mu$ m. (D) Western blots on whole cell extracts of MCF7 cells. Cell extracts were prepared following 24 hours culture in the presence of HAT inhibitors (or vehicle control) at the indicated concentrations. Specific antibodies were used to detect bulk levels of H3K18Ac, H4K16Ac and H3K9Ac. Densitometry measurements were performed using Image J software [21]. The level of each histone PTM in controls (vehicle only, normalised to a loading control) was set to 1. (E) Western blots showing bulk levels of H3K18Ac in whole cell extracts of U2OS and SaOS2 osteosarcoma cells following exposure to $10 \mu \mathrm{M}$ or $20 \mu \mathrm{M}$ curcumin or garcinol (as indicated in increasing scale). Actin loading controls are also shown, and the data were quantified by Image $J$ as in (D) 
through S phase [22], may account for the growth arrest induced by garcinol, whereas curcumin-induced growth arrest appears to involve a distinct mechanism.

In common with other cancer cell lines [6] and breast tumours [7], MCF7 cells exhibit low levels of acetylated H4K16 by immunofluorescence staining (Figure 2B\&C). However, bulk levels of H4K16Ac were increased after exposure to curcumin or garcinol as observed by immunofluorescence (Figure 2B\&C) and western blotting (Figure 2D) consistent with the moderate increase in pan-acetyl H4 levels (Figure 2A). These results indicate that selected H3 and H4 PTMs are differentially affected by curcumin and garcinol.

DNA damage signaling pathways are induced by garcinol The failure of garcinol-treated cells to complete S-phase, coupled with loss of H3K18 acetylation and enhanced acetylation of H4K16 prompted us to compare DNA damage signaling markers in HAT inhibitor-treated or control MCF7 cells. As shown in Figure 3A, curcumin and garcinol induced a dose-dependent increase in the number and intensity of nuclear $\gamma \mathrm{H} 2 \mathrm{~A}$.X foci, consistent with replication stress-associated DNA damage [23]. This was confirmed by western blotting, with a strong increase in $\gamma$ H2A.X phosphorylation observed after exposure to garcinol (Figure 3B). Garcinol also increased the levels of another DNA damage associated histone PTM, i.e. H3K56Ac (Figure 3B). Thus, inhibition of cell proliferation by garcinol is accompanied by a DNA damage signaling response in MCF7 cells.

\section{Garcinol alters expression and acetylation of tumour suppressor $\mathrm{p} 53$}

The transcription factor $\mathrm{p} 53$ is an important regulator of cell fate decisions that also shows enhanced expression in response to DNA damage. Western blotting revealed a strong induction of p53 expression in MCF7 cells treated with garcinol (Figure 3D). Like histones, p53 function is regulated by lysine acetylation, which impacts on its function in transcription, DNA damage checkpoints and cell fate decisions. Acetylation of lysines in the C-terminal activation domain of p53 (K370, K372, $\mathrm{K} 373, \mathrm{~K} 381, \mathrm{~K} 382$ ) is mediated by $\mathrm{CBP} / \mathrm{p} 300$ and PCAF and promotes transcriptional activation of p53 target genes [24]. However acetylation of p53 at K120 within the DNA binding domain can be catalysed by TIP60 in response to DNA damage, and has been implicated in activation of pro-apoptotic pathways both dependent on and independent of transcription [25-27]. Western blots further revealed that the $\mathrm{K} 120$-acetylated form of p53 is readily detected after garcinol treatment (Figure 3D), and correlated with increased expression of TIP60 (Figure 3C), whereas no changes in the levels of other chromatin regulators such as the MYST family HAT, hMOF or the deacetylase SIRT1, were observed (Figure 3C). Acetylation of the p53 C-terminal residues $\mathrm{K} 373 / 382$ was observed to be reduced by garcinol, consistent with its inhibitory effect on CBP/p300 activity (Figure 3D). Immunocytochemical staining revealed that the K120acetylated form of p53 was only detected strongly after garcinol treatment, and was localised to the cytoplasm (Figure 3E\&F). Consistent with the western data, increased expression of TIP60 was also observed in the garcinol-treated cells, but not controls (Figure 3E). Taken together, these results suggest that garcinol has pleiotropic effects on breast cancer cells. Inhibition of $\mathrm{CBP} / \mathrm{p} 300$ activity results in hypoacetylation of both histone and non-histone targets such as H3K18 and the C-terminus of p53, consistent with reduced gene transcription [18]. In addition, garcinol induces replication stress and DNA damage, resulting in upregulation of the DNA damage signals $(\gamma \mathrm{H} 2 \mathrm{~A} . \mathrm{X}, \mathrm{H} 4 \mathrm{~K} 16 \mathrm{Ac}$, H3K56Ac) and associated proteins (TIP60, p53). The observed switch in p53 acetylation from C-terminus to DNA binding domain is consistent with altered functionality of p53 from transcription activator to growth arrest/apoptosis.

\section{SUV42OH2 mediates H4K20 trimethylation induced by garcinol}

In addition to effects on histone acetylation, we assessed whether garcinol might affect H4K20 trimethylation, as this PTM is reduced in cancer cell lines [6]. Immunostaining of control (vehicle-treated) cells indicated a relatively low detection level of this PTM in MCF7 cells. Unexpectedly, a strong dose-dependent enhancement of H4K20Me3 was detected after exposure of cells to garcinol for 24 hours (Figure 4A). Western blotting confirmed the garcinol-dependent induction of H4K20Me3, whereas no dramatic change in the level of trimethylated H3K9 was detected (Figure 4B). This induction of $\mathrm{H} 4 \mathrm{~K} 20 \mathrm{Me} 3$ was unexpected as garcinol is not known to have direct effects on the activity of lysine methyltransferases, thus we reasoned that this might be due to an indirect mechanism, such as by affecting the expression of chromatin modifying enzymes.

Trimethylation of H4K20 in mammalian cells is catalysed by SUV420H2 $[28,29]$. As shown in Figure 4C, garcinol treatment of MCF7 cells resulted in a concomitant increase in both SUV420H2 and H4K20Me3. This was confirmed by flow cytometry/immunostaining of permeabilised cells, which detected an approximate 3-fold increase in the number of MCF7 cells expressing high levels of SUV420H2 protein, and an almost 10-fold increase in H4K20Me3 positive cells (Figure 4D). Similar induction of H4K20Me3 was observed in MCF7 cells treated with garcinol analogs (data not shown). These 


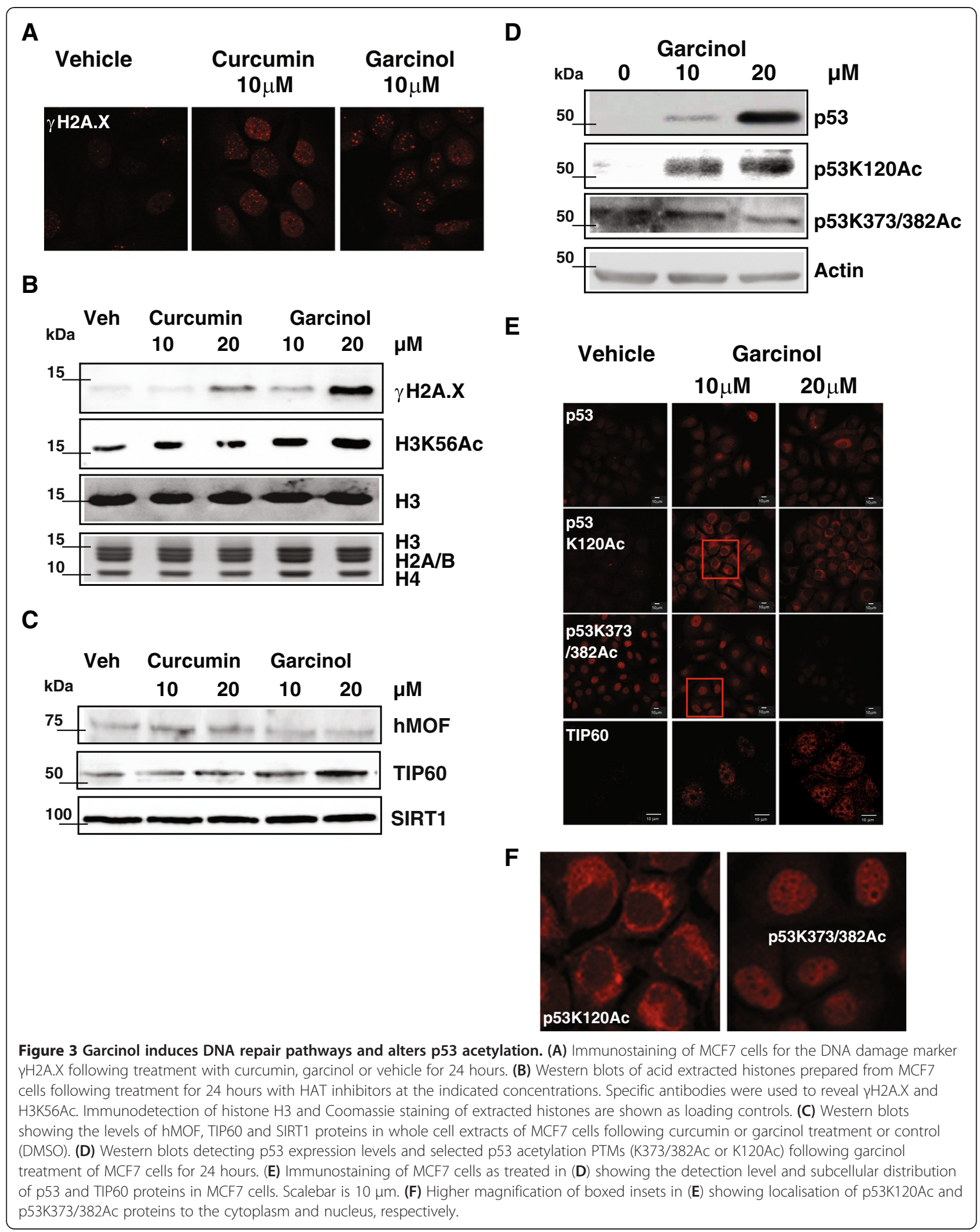




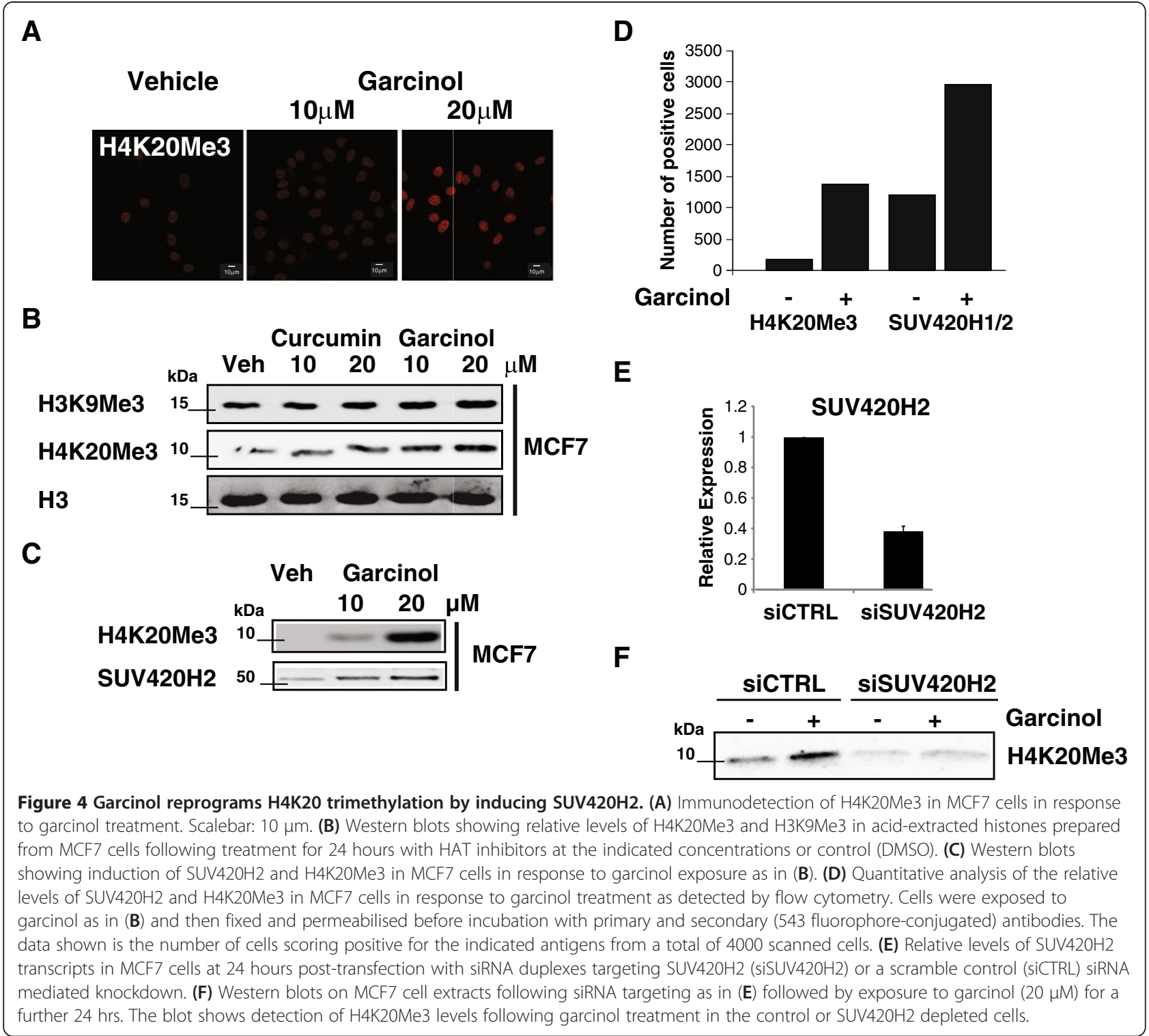

results indicate that increased SUV420H2 expression is likely to be responsible for the bulk increase in H4K20Me3 observed after garcinol treatment.

To test this hypothesis, siRNA duplexes were used to reduce the expression of $\mathrm{SUV} 420 \mathrm{H} 2$. As shown in Figure 4E. SUV420H2 was successfully knocked down by a specific but not a control siRNA pool as measured by RT-qPCR. MCF7 cells were transfected with control or SUV420H2 siRNAs and subsequently treated with garcinol. Increased levels of H4K20Me3 following treatment with garcinol were observed in the control, however H4K20Me3 levels were strongly attenuated in the SUV420H2 knockdown (Figure 4F). Taken together our results indicate that SUV420H2 expression is induced after treatment of MCF7 cells with garcinol, and is responsible for the concomitant increase in trimethylation of H4K20. Thus, we conclude that garcinol treatment induces changes in expression levels of chromatin modifying enzymes in MCF7 cells, which drive changes in histone PTMs associated with DNA damage/repair responses and cell growth arrest.

\section{Discussion}

Natural products are an important resource for the discovery of new leads for cancer therapies. Although garcinol has been shown to have cancer chemopreventive properties in animal models [30], its biological action remains poorly understood. While garcinol may have pleiotropic effects in cells due to its moderate antioxidant properties [31], the discovery that it can directly inhibit histone acetylation by p300 [16,17], indicates that it may impact directly on global histone 
modifications, and thus gene regulatory processes in tumour cells. However, significant gaps remain in our understanding of the biological effects of garcinol and related molecules on cell function.

A recent report showed that garcinol can block the proliferation of MCF7 breast cancer cells in culture [32]. Using concentrations of garcinol in excess of $25 \mu \mathrm{M}$, significant MCF7 cell apoptosis was observed [32]. In this study we confirmed the growth inhibitory effects of garcinol against MCF7 cells (Figure 1A), and established that garcinol is cytotoxic to these cells when used at concentrations in excess of $20 \mu \mathrm{M}$, inducing substantial loss of cell adherence and cell lysis (data not shown). As this precludes accurate measurement of the effects of garcinol on histone PTMs by western blot and immunocytochemical analyses, we performed experiments at subcytotoxic levels of garcinol $(=$ or $<20 \mu \mathrm{M})$ to better understand its effects on lysine acetylation targets in MCF7 cells.

The reduced proliferation of MCF7 cells observed in MTT assays was confirmed by a dramatic decrease in the number of cells entering S-phase, as detected by BrdU incorporation in flow cytometry analyses (Figure $1 \mathrm{~B} \& \mathrm{C}$ ). However, the data suggested that the biological effects of curcumin and garcinol/LTK14 in these cells may be distinct. Curcumin-arrested cells showed an enhanced accumulation in G2/M, whereas cells treated with garcinol-related compounds arrested in G1. Similarly, HEPG2 cells have also been reported to arrest in G2/M after treatment with curcumin [33]. It is also worth noting that curcumin differed from garcinol in that it appeared to stimulate the growth of MCF7 cells at the lowest concentration tested $(2 \mu \mathrm{M})$ (Figure $1 \mathrm{~A})$. This may be consistent with reports that low levels of curcumin can stimulate proliferation of other cell types, including neural progenitors [34] and 3T3-L1 preadipocytes [35]. Consistent with its anti-proliferative effects on a range of other cancer cell lines, curcumin blocked MCF7 cell growth at higher doses $(10-20 \mu \mathrm{M})$ (Figure 1A). These results highlight the importance of considering the bioavailability of HAT inhibitor compounds to select dose ranges that inhibit rather than promote the growth of malignant cells.

Targeting of histone modifying enzymes is an area of emerging interest in the development of anticancer drugs. Pan-inhibitors of deacetylases (HDACs) have shown promise in preclinical models and have entered clinical trials. The involvement of CBP, p300, MOZ and MORF genes in chromosomal translocations associated with leukaemia [36] suggests that inhibitors of acetyltransferase enzymes may also have cancer chemopreventive properties. However, little is known regarding the biological effects of currently available lysine acetyltransferase inhibitors, such as garcinol. Consistent with previous studies on other cell types [16-18], we have shown here that treatment of MCF7 cells with curcumin or garcinol can lead to a dose-dependent reduction in bulk levels of histone acetylation, as determined using pan-acetylH3 and pan-acetylH4 antibodies (Figure 2A). Remarkably however, these compounds were found to have differential effects on bulk levels of selected PTMs encountered in histones $\mathrm{H} 3$ and $\mathrm{H} 4$ (Figures 2, 3, 4). While curcumin had no obvious negative effect on H3K18 acetylation at the concentrations tested, garcinol treatment resulted in $\mathrm{H} 3 \mathrm{~K} 18$ hypoacetylation in three cancer cell lines tested (Figure 2B,D\&E). In contrast, neither compound was found to substantially affect H3K9 acetylation (Figure 2B\&D). Acetylation of H3K9 has been shown to be catalysed by GCN5 [37] which is insensitive to garcinol $[17,18]$. Interestingly, recent studies have shown that acetylation of $\mathrm{H} 3 \mathrm{~K} 18$ by $\mathrm{CBP} / \mathrm{p} 300$ is required for the activation of $\mathrm{S}$ phase in quiescent fibroblast cells $[22,38]$. Thus, garcinol inhibition of CBP/ p300-mediated acetylation of H3K18 may be a contributary factor in the failure of MCF7 cells to proceed through $\mathrm{S}$ phase.

Although pan-acetylation of $\mathrm{H} 4$ was observed to be reduced by both curcumin and garcinol at $10 \mu \mathrm{M}$, we noted that at $20 \mu \mathrm{M}$ this inhibitory effect was not as clear (Figure 2A). This anomalous result suggested differential dose-dependent effects of HAT inhibitors on $\mathrm{H} 4$ acetylation, and highlights the disadvantage of using pan-acetyl $\mathrm{H} 3 / \mathrm{H} 4$ antibodies in that effects on specific histone PTMs can be masked. However, as shown in Figure $2 \mathrm{~B} \& \mathrm{C}, \mathrm{H} 4 \mathrm{~K} 16$ acetylation, which is known to be reduced in cancer cell lines [6], was barely detectable in control MCF7 cells at the concentration of antibody used. However, acetylated H4K16 was readily detected after treatment with curcumin (Figure 2B) or garcinol (Figure 2B\&C). Acetylation of H4K16 is normally established by hMOF $[39,40]$ although in conditions of cell stress other HATs can target this modification, e.g. the DNA damage-associated TIP60. We did not detect any change in the expression levels of hMOF after treatment with garcinol, whereas TIP60 expression appeared to be elevated (Figure 3C\&E). Thus increased expression of TIP60 or other HATs may account for the increase in H4K16 acetylation. Although we also attempted to knock down TIP60 transcripts using siRNA in garcinoltreated cells, we did not observe a reduction in TIP60 protein levels by western blotting over the time course of the experiment (data not shown), thus we were unable to establish definitively whether TIP60 is responsible for the observed increase in H4K16Ac.

The observed elevation of $\gamma \mathrm{H} 2 \mathrm{~A} . \mathrm{X}$ foci in MCF7 cells exposed to garcinol (Figure $3 \mathrm{~A} \& \mathrm{~B}$ ) is consistent with an increased incidence of DNA double strand breaks, likely associated with replicative stress [23]. Interestingly, acetylation of H2A.X by TIP60 has been 
reported to be required for phosphorylation of H2A.X S139 in response to DNA damage [41,42]. TIP60 is also responsible for acetylation of the DNA binding domain of p53 at K120 [27]. Our observations that garcinol induces expression of p53 and TIP60 in MCF7 cells (Figure 3C-E), accompanied by increased acetylation of p53K120 and its accumulation in the cytoplasm (Figure 3E\&F), suggests that TIP60 may drive this switch in $\mathrm{p} 53$ function. This is consistent with other studies revealing that $\mathrm{p} 53 \mathrm{~K} 120$ is acetylated by TIP60 and that this is important for the apoptotic functions of p53 in response to DNA damage [27]. It has also been shown that p53K120Ac is enriched in the cytoplasm and associated with mitochondria where it impacts on apoptotic pathways [26]. We conclude that the garcinol-induced blockade of $\mathrm{CBP} / \mathrm{p} 300$ inhibits acetylation of the p53 C-terminus and coupled with upregulation of TIP60 or other HATs, is likely to promote an acetylation-mediated switch in p53 function.

A surprising observation in our study was that garcinol also impacts on histone methylation, specifically trimethylation of H4K20 (Figure 4A-C). We have shown that this is due to the induced expression of SUV420H2 (Figure 4C-F), one of the major enzymes targeting H4K20 for multiple methylation. Like H4K16Ac, H4K20Me3 has been implicated in the repair of DNA damage [11] and cell senescence [43], both PTMs impact on chromatin structure [44,45], and a recent study has demonstrated their interdependence in gene transcription [46]. However, the consequences of reduced incidence of $\mathrm{H} 4 \mathrm{~K} 20 \mathrm{Me} 3$ and H4K16Ac in breast tumours [7] remains to be determined.

\section{Conclusion}

Our study indicates that in addition to inhibition of CBP/p300 acetyltransferase activity, garcinol has multiple biological effects in cancer cells, including the activation of DNA damage signaling and the induction of chromatin regulators such as TIP60 and SUV420H2. Moreover, we have provided proof of principle that histone PTM signatures associated with cancer can be reprogrammed by the natural product garcinol, a dietary compound with a traditional use as a chemopreventive agent.

\footnotetext{
Abbreviations

BrdU: Bromodeoxyuridine; BSA: Bovine serum albumin; CBP: CREB-binding protein; CREB: Cyclic AMP-response element-binding protein; DMSO: Dimethylsulfoxide; FITC: Fluorescein isothiocyanate; GCN5: General control of nitrogen metabolism 5; HAT: Histone acetyltransferase; HDAC: Histone deacetylase; MOF: Males absent on the first; MORF: Monocytic leukemia zinc finger protein-related factor; MOZ: Monocytic leukemia zinc finger protein; MTT: 3-(4,5-dimethylthiazol-2-yl)-2,5-di phenyltetrazolium bromide; O.D.: Optical density; PBS: Phosphate buffered saline; PCAF: p300/CBP-associated factor; SUV4-20H2: Suppressor of variegation 4-20 H2; siRNA: Small inhibitory RNA; TIP60: HIV Tat-interacting protein 60.
}

\section{Competing interests}

The authors declare that they have no competing interests.

\section{Author' contributions}

HMC, MKA \& DMH conceived and designed experiments and prepared figures. HMC, MKA, MM, SED, AA, KBK, BY and GSW performed experiments and analysed data. KM and TKK prepared and provided unique research materials. HMC and DMH wrote the manuscript. MKA, GSW and TKK helped edit the manuscript, and the final version was approved by all authors.

\section{Authors' information}

HMC and MKA are equal first authors.

\section{Acknowledgments}

This work was supported by grants from Cancer Research UK (DMH, MM) Leukaemia Lymphoma Research (DMH, HMC), the Medical Research Council (DMH, BY) the Association for International Cancer Research (DMH, KBK; GSW, AA). MKA was supported by a fellowship from the Egyptian Government. SED was supported by a studentship from the BBSRC. TKK is a recipient of the Sir J.C Bose National Fellowship (Department of Science and Technology, Government of India). The funding bodies had no part in the design, execution or analysis of the data, preparation or submission of the manuscript.

\section{Author details}

${ }^{1}$ Gene Regulation Group, Centre for Biomolecular Sciences, School of Pharmacy, University of Nottingham, University Park, Nottingham NG7 2RD, United Kingdom. ${ }^{2}$ Transcription and Disease Laboratory, Jawaharlal Nehru Centre for Advanced Scientific Research, Bangalore 560064, Karnataka, India. ${ }^{3}$ Present address: Department of Pathology, Faculty of Medicine, Suez Canal University, Ismailia, Egypt.

Received: 24 April 2012 Accepted: 25 January 2013

Published: 29 January 2013

\section{References}

1. Kouzarides T: Chromatin modifications and their function. Cell 2007, 128:693-705.

2. Jenuwein T, Allis CD: Translating the histone code. Science 2001, 293:1074-1080.

3. Tjeertes JV, Miller KM, Jackson SP: Screen for DNA-damage-responsive histone modifications identifies H3K9Ac and H3K56Ac in human cells. EMBO J 2009, 28:1878-1889.

4. Taverna SD, Li H, Ruthenburg AJ, Allis CD, Patel DJ: How chromatin-binding modules interpret histone modifications: lessons from professional pocket pickers. Nat Struct Mol Biol 2007, 14:1025-1040.

5. van Attikum H, Gasser SM: Crosstalk between histone modifications during the DNA damage response. Trends Cell Biol 2009, 19:207-217.

6. Fraga MF, Ballestar E, Villar-Garea A, Boix-Chornet M, Espada J, Schotta G, Bonaldi T, Haydon C, Ropero S, Petrie K, et al: Loss of acetylation at Lys 16 and trimethylation at Lys 20 of histone $\mathrm{H} 4$ is a common hallmark of human cancer. Nat Genet 2005, 37:391-400.

7. Elsheikh SE, Green AR, Rakha EA, Powe DG, Ahmed RA, Collins HM, Soria D, Garibaldi JM, Paish CE, Ammar AA, et al: Global histone modifications in breast cancer correlate with tumor phenotypes, prognostic factors, and patient outcome. Cancer Res 2009, 69:3802-3809.

8. Seligson DB, Horvath S, Shi T, Yu H, Tze S, Grunstein M, Kurdistani SK: Global histone modification patterns predict risk of prostate cancer recurrence. Nature 2005, 435:1262-1266.

9. Barlesi F, Giaccone G, Gallegos-Ruiz MI, Loundou A, Span SW, Lefesvre P, Kruyt FA, Rodriguez JA: Global histone modifications predict prognosis of resected non small-cell lung cancer. J Clin Oncol 2007, 25:4358-4364.

10. Park YS, Jin MY, Kim YJ, Yook JH, Kim BS, Jang SJ: The global histone modification pattern correlates with cancer recurrence and overall survival in gastric adenocarcinoma. Ann Surg Oncol 2008, 15:1968-1976.

11. Sharma GG, So S, Gupta A, Kumar R, Cayrou C, Avvakumov N, Bhadra U, Pandita RK, Porteus MH, Chen DJ, et al: MOF and histone $\mathrm{H} 4$ acetylation at lysine 16 are critical for DNA Damage Response and DSB Repair. Mol Cell Biol 2010, 30:3582-3585. 
12. Sanders SL, Portoso M, Mata J, Bahler J, Allshire RC, Kouzarides T: Methylation of histone $\mathrm{H} 4$ lysine 20 controls recruitment of $\mathrm{Crb} 2$ to sites of DNA damage. Cell 2004, 119:603-614.

13. Heery DM, Fischer PM: Pharmacological targeting of lysine acetyltransferases in human disease: a progress report. Drug Discov Today 2007, 12:88-99.

14. Hodawadekar SC, Marmorstein R: Chemistry of acetyl transfer by histone modifying enzymes: structure, mechanism and implications for effector design. Oncogene 2007, 26:5528-5540.

15. Arif M, Pradhan SK, Thanuja GR, Vedamurthy BM, Agrawal S, Dasgupta D, Kundu TK: Mechanism of p300 specific histone acetyltransferase inhibition by small molecules. J Med Chem 2009, 52:267-277.

16. Balasubramanyam K, Varier RA, Altaf M, Swaminathan V, Siddappa NB, Ranga U, Kundu TK: Curcumin, a novel p300/CREB-binding proteinspecific inhibitor of acetyltransferase, represses the acetylation of histone/nonhistone proteins and histone acetyltransferase-dependent chromatin transcription. J Biol Chem 2004, 279:51163-51171.

17. Balasubramanyam K, Altaf M, Varier RA, Swaminathan V, Ravindran A Sadhale PP, Kundu TK: Polyisoprenylated benzophenone, garcinol, a natural histone acetyltransferase inhibitor, represses chromatin transcription and alters global gene expression. J Biol Chem 2004, 279:33716-33726.

18. Mantelingu K, Reddy BA, Swaminathan V, Kishore AH, Siddappa NB, Kumar GV, Nagashankar G, Natesh N, Roy S, Sadhale PP, et al: Specific inhibition of p300HAT alters global gene expression and represses HIV replication. Chem Biol 2007, 14:645-657.

19. Shechter D, Dormann HL, Allis CD, Hake SB: Extraction, purification and analysis of histones. Nat Protoc 2007, 2:1445-1457.

20. Aslam A, Mittal S, Koch F, Andrau JC, Winkler GS: The Ccr4-not deadenylase subunits CNOT7 and CNOT8 have overlapping roles and modulate cell proliferation. Mol Biol Cell 2009, 20:3840-3850.

21. Schneider CA, Rasband WS, Eliceiri KW: NIH Image to ImageJ: 25 years of image analysis. Nat Methods 2012, 9:671-675.

22. Horwitz GA, Zhang K, McBrian MA, Grunstein M, Kurdistani SK, Berk AJ: Adenovirus small e1a alters global patterns of histone modification. Science 2008, 321:1084-1085.

23. Ewald B, Sampath D, Plunkett W: H2AX phosphorylation marks gemcitabine-induced stalled replication forks and their collapse upon S-phase checkpoint abrogation. Mol Cancer Ther 2007, 6:1239-1248.

24. Gu W, Roeder RG: Activation of p53 sequence-specific DNA binding by acetylation of the p53 C-terminal domain. Cell 1997, 90:595-606.

25. Sykes SM, Mellert HS, Holbert MA, Li K, Marmorstein R, Lane WS, McMahon SB: Acetylation of the p53 DNA-binding domain regulates apoptosis induction. Mol Cell 2006, 24:841-851.

26. Sykes SM, Stanek TJ, Frank A, Murphy ME, McMahon SB: Acetylation of the DNA binding domain regulates transcription-independent apoptosis by p53. J Biol Chem 2009, 284:20197-20205.

27. Tang Y, Luo J, Zhang W, Gu W: Tip60-dependent acetylation of p53 modulates the decision between cell-cycle arrest and apoptosis. Mol Cell 2006, 24:827-839.

28. Pesavento JJ, Yang $\mathrm{H}$, Kelleher NL, Mizzen CA: Certain and progressive methylation of histone $\mathrm{H} 4$ at lysine 20 during the cell cycle. $\mathrm{Mol} \mathrm{Cell} \mathrm{Biol}$ 2008, 28:468-486.

29. Tsang LW, Hu N, Underhill DA: Comparative analyses of SUV420H1 isoforms and SUV420H2 reveal differences in their cellular localization and effects on myogenic differentiation. PLoS One 2010, 5:e14447.

30. Yoshida K, Tanaka T, Hirose Y, Yamaguchi F, Kohno H, Toida M, Hara A Sugie S, Shibata T, Mori H: Dietary garcinol inhibits 4-nitroquinoline 1-oxide-induced tongue carcinogenesis in rats. Cancer Lett 2005, 221:29-39.

31. Yamaguchi F, Ariga T, Yoshimura Y, Nakazawa H: Antioxidative and antiglycation activity of garcinol from Garcinia indica fruit rind. J Agric Food Chem 2000, 48:180-185.

32. Ahmad A, Wang Z, Ali R, Maitah MY, Kong D, Banerjee S, Padhye S, Sarkar FH: Apoptosis-inducing effect of garcinol is mediated by NF-kappaB signaling in breast cancer cells. J Cell Biochem 2010, 109:1134-1141.

33. Sahu RP, Batra S, Srivastava SK: Activation of ATM/Chk1 by curcumin causes cell cycle arrest and apoptosis in human pancreatic cancer cells. Br J Cancer 2009, 100:1425-1433.

34. Kim SJ, Son TG, Park HR, Park M, Kim MS, Kim HS, Chung HY, Mattson MP, Lee J: Curcumin stimulates proliferation of embryonic neural progenitor cells and neurogenesis in the adult hippocampus. J Biol Chem 2008, 283:14497-14505

35. Kim JH, Park SH, Nam SW, Kwon HJ, Kim BW, Kim WJ, Choi YH: Curcumin stimulates proliferation, stemness acting signals and migration of 3T3-L1 preadipocytes. Int J Mol Med 2011, 28:429-435.

36. Troke PJ, Kindle KB, Collins HM, Heery DM: MOZ fusion proteins in acute myeloid leukaemia. Biochem Soc Symp 2006, 23-39.

37. Jin Q, Yu LR, Wang L, Zhang Z, Kasper LH, Lee JE, Wang C, Brindle PK, Dent SY, Ge K: Distinct roles of GCN5/PCAF-mediated H3K9ac and CBP/p300mediated H3K18/27ac in nuclear receptor transactivation. EMBO J 2011, 30:249-262.

38. Ferrari R, Pellegrini M, Horwitz GA, Xie W, Berk AJ, Kurdistani SK: Epigenetic reprogramming by adenovirus e1a. Science 2008, 321:1086-1088.

39. Taipale M, Rea S, Richter K, Vilar A, Lichter P, Imhof A, Akhtar A: hMOF histone acetyltransferase is required for histone $\mathrm{H} 4$ lysine 16 acetylation in mammalian cells. Mol Cell Biol 2005, 25:6798-6810.

40. Smith ER, Cayrou C, Huang R, Lane WS, Cote J, Lucchesi JC: A human protein complex homologous to the Drosophila MSL complex is responsible for the majority of histone $\mathrm{H} 4$ acetylation at lysine 16 . Mol Cell Biol 2005, 25:9175-9188.

41. Kusch T, Florens L, Macdonald WH, Swanson SK, Glaser RL, Yates JR 3rd, Abmayr SM, Washburn MP, Workman JL: Acetylation by Tip60 is required for selective histone variant exchange at DNA lesions. Science 2004, 306:2084-2087.

42. Ikura T, Tashiro S, Kakino A, Shima H, Jacob N, Amunugama R, Yoder K, Izumi S, Kuraoka I, Tanaka K, et al: DNA damage-dependent acetylation and ubiquitination of $\mathrm{H} 2 \mathrm{AX}$ enhances chromatin dynamics. Mol Cell Biol 2007, 27:7028-7040.

43. Kozak ML, Chavez A, Dang W, Berger SL, Ashok A, Guo X, Johnson FB: Inactivation of the Sas2 histone acetyltransferase delays senescence driven by telomere dysfunction. EMBO J 2010, 29:158-170.

44. Shogren-Knaak M, Ishii H, Sun JM, Pazin MJ, Davie JR, Peterson CL: Histone H4-K16 acetylation controls chromatin structure and protein interactions. Science 2006, 311:844-847.

45. Lu X, Simon MD, Chodaparambil JV, Hansen JC, Shokat KM, Luger K: The effect of H3K79 dimethylation and H4K20 trimethylation on nucleosome and chromatin structure. Nat Struct Mol Biol 2008, 15:1122-1124.

46. Kapoor-Vazirani P, Kagey JD, Vertino PM: SUV42OH2-mediated H4K20 trimethylation enforces RNA polymerase II promoter-proximal pausing by blocking hMOF-dependent H4K16 acetylation. Mol Cell Biol 2011, 31:1594-1609.

doi:10.1186/1471-2407-13-37

Cite this article as: Collins et al:: Differential effects of garcinol and curcumin on histone and p53 modifications in tumour cells. BMC Cancer 2013 13:37.

\section{Submit your next manuscript to BioMed Central and take full advantage of:}

- Convenient online submission

- Thorough peer review

- No space constraints or color figure charges

- Immediate publication on acceptance

- Inclusion in PubMed, CAS, Scopus and Google Scholar

- Research which is freely available for redistribution 